\title{
Dermoid Cyst
}

National Cancer Institute

\section{Source}

National Cancer Institute. Dermoid Cyst. NCI Thesaurus. Code C9011.

A mature teratoma characterized by the presence of a cyst which is lined by mature tissue resembling the epidermis and the epidermal appendages. It occurs in the ovary, testis, and extragonadal sites including central nervous system and skin. 